\title{
Mononucleotide Marker Name
}

National Cancer Institute

\section{Source}

National Cancer Institute. Mononucleotide Marker Name. NCI Thesaurus. Code C150830.

The literal identifier of the mononucleotide marker of interest. 